\title{
Kelayakan Instrumen Evaluasi Buku Sekolah Elektronik (BSE) Bahasa Indonesia Siswa SMA Kelas XI
}

\author{
The Feasibility Evaluation Instruments of Indonesian Electronic School Book for Class \\ XI High Schools Students
}

\author{
Fernanda Yusi Listeani ${ }^{1, *}$, Imam Safi'i' ${ }^{2}$, dan Nini Ibrahim ${ }^{3}$ \\ ${ }^{1,2,3}$ Universitas Muhammadiyah Prof. Dr. HAMKA, Jakarta \\ ${ }^{1}$ Correspondence email: fernandamp8@gmail.com \\ 2Email: imamsafii2077@uhamka.ac.id \\ ${ }^{3}$ Email: niniibrahim13@gmail.com
}

Received: 25 April 2021 Accepted: 2 July 2021 Published: 5 August 2021

\begin{abstract}
Curriculum development is directed at the condition of society in shaping the younger generation. The development of the curriculum also has implications for textbooks. Textbooks are an element of supporting educational facilities and infrastructure. This study aims to describe the feasibility of the Evaluation Instrument in the Indonesian Electronic School Book for SMA class XI students of the 2017 revision of the 2013 Curriculum. This research uses a qualitative approach with the method of Content Analysis. Data collection techniques are using literature study techniques and document techniques. The sample of this research was carried out purposively by determining the criteria according to the research objectives. The sample of this research is an evaluation instrument in the Indonesian language BSE of high school students class XI 2013 revision of the 2017 Curriculum. The data of this research are the feasibility of the evaluation instrument in terms of material aspects and language aspects. The percentage of eligibility level is done by dividing the number of scores obtained by the number of total criteria score then multiplied by one hundred. The results showed that the feasibility of the evaluation instrument in terms of the material aspect was $78.8 \%$ and in terms of the language aspect was $84.7 \%$. Based on the research results of the BSE Indonesian evaluation instrument, Class XI high school students are categorized as feasible but must be accompanied by other learning resources. Such as the Internet, Print Media, etc. The results of this study can be used as one of the foundations for teachers to study and consider student textbooks, especially the feasibility of evaluation instruments.
\end{abstract}

Keywords: Indonesian, electronic school book for high school student, the feasibility of evaluation instruments

\begin{abstract}
Abstrak: Perkembangan kurikulum diarahkan pada kondisi masyarakat dalam membentuk generasi muda. Perkembangan kurikulum berimplikasi juga pada buku teks. Buku teks merupakan unsur penunjang sarana dan prasarana pendidikan. Penelitian ini bertujuan mendeskripsikan kelayakan Instrumen Evaluasi dalam Buku Sekolah Elektronik (BSE) Bahasa Indonesia siswa SMA kelas XI Kurikulum 2013 revisi 2017. Penelitian ini menggunakan pendekatan kualitatif dengan metode Content Analysiys. Teknik pengumpulan data menggunakan teknik studi pustaka dan teknik dokumen. Sampel penelitian ini dilakukan purposif dengan cara menetapkan kriteria sesuai tujuan penelitian. Sampel penelitian ini adalah instrumen evaluasi dalam BSE Bahasa Indonesia siswa SMA kelas XI Kurikulum 2013 revisi 2017. Data penelitian ini adalah kelayakan instrumen evaluasi ditinjau dari aspek materi dan aspek bahasa. Persentase tingkat kelayakan dilakukan dengan cara membagi jumlah pemerolehan skor dengan banyaknya jumlah total skor kriteria kemudian dikalikan seratus. Hasil penelitian menunjukkan Kelayakan Instrumen Evaluasi ditinjau dari aspek materi sebesar 78,8\% dan ditinjau dari aspek bahasa sebesar 84,7\%. Berdasarkan hasil penelitian instrumen evaluasi BSE Bahasa Indonesia siswa SMA Kelas XI dikategorikan layak namun harus dengan pendamping sumber belajar yang lain. Seperti Internet, Media Cetak, dll. Hasil penelitian ini dapat dijadikan sebagai salah satu landasan guru dalam menelaah dan mempertimbangkan buku ajar siswa terutama kelayakan instrumen evaluasi.
\end{abstract}

Kata kunci: bahasa Indonesia, buku sekolah elektronik siswa SMA, kelayakan instrumen evaluasi

To cite this article:

Listeani, F. Y., Safi'i, I., \& Ibrahim, N. (2021). Kelayakan Instrumen Evaluasi Buku Sekolah Elektronik (BSE) Bahasa Indonesia Siswa SMA Kelas XI. Diglosia: Jurnal Kajian Bahasa, Sastra, dan Pengajarannya, 4(3), 365-386. https://doi.org/10.30872/diglosia.v4i3.216 


\section{A. PENDAHULUAN}

Perkembangan kurikulum diarahkan pada kondisi masyarakat dalam membentuk generasi muda. Indonesia telah mengalami beberapa kali perubahan kurikulum. Perkembangan kurikulum berimplikasi juga pada buku teks. Buku teks Bahasa tidak hanya mempelajari cara untuk belajar bahasa namun juga dapat menjadi media untuk mengintegrasikan pengetahuan lintas disiplin dan memperkenalkan keragaman dan toleransi budaya (Huang, 2019). Buku teks yang berkualitas harus memenuhi beberapa komponen. Salah satunya, instrumen evaluasi sebagai bahan pengayaan pembelajaran. Buku teks terdapat evaluasi, evaluasi merupakan aspek penting dalam pembelajaran di sekolah. Daya serap siswa dalam memahami pembelajaran dapat mencerminkan evaluasi pembelajaran. Hasil evaluasi pembelajaran dapat digunakan untuk menentukan pilihan yang tepat dalam pengambilan keputusan untuk memperbaiki kinerja satuan pendidikan (Suharsimi \& Jabar, 2010). Alat evaluasi yang digunakan menentukan keberhasilan evaluasi. Alat evaluasi/instrumen evaluasi berguna untuk mengukur dan mengevaluasi sesuatu sesuai dengan keadaan (Yusuf, 2017). Untuk mendapatkan hasil maksimal dalam melakukan evaluasi maka perlu terlebih dahulu memvalidkan instrumen evaluasi. Sistem penilaian dalam buku Sekolah Elektronik (BSE) Bahasa Indonesia siswa SMA Kelas XI Kurikulum 2013 revisi 2017 mengacu pada penilaian kurikulum 2013, yaitu asessment as learning.

Asessment as learning memandu siswa melakukan monitor dan refleksi dalam proses belajar secara mandiri. Pembelajaran yang menekankan pada penggunaan asesmen sebagai proses perkembangan dan penunjang metakognisi siswa (Lorna, 2013). Saat mengevaluasi kemampuan siswa, soal yang digunakan harus valid dari segi isi (validitas isi). Soal yang valid pun harus mengikuti kaidah penulisan soal yang benar. Kelayakan instrumen evaluasi adalah layak atau tidaknya instrumen evaluasi yang digunakan sebagai alat ukur keberhasilan atau tingkat ketercapaian dari pembelajaran. Kajian tentang kelayakan instrumen evaluasi yang terdapat dalam buku teks sangat penting dilakukan. Instrumen evaluasi dalam buku teks merupakan penunjang bahan ajar yang dapat digunakan sebagai sarana latihan untuk meningkatkan kompetensi siswa (Safari, 2019). Oleh karena itu, penelitian secara mendalam tentang kualitas instrumen evaluasi dalam buku teks perlu dilakukan khususnya Buku Teks Bahasa Indonesia siswa kelas XI kurikulum 2013 revisi 2017.

Kelayakan instrumen evaluasi perlu mendapat perhatian khusus dalam pembelajaran bahasa. Dalam mengukur kelayakan, kesesuaian, efisiensi, dan kemantapan suatu instrumen evaluasi diperlukan pelbagai macam kevaliditasan. Validitas merupakan suatu butir instrumen penilaian yang tercermin dari hasil pengukuran yang mencerminkan fakta atau keadaan sebenarnya dari yang diukur (Supardi, 2019). Validitas mencangkum keakuratan instrumen dalam mengukur kriteria yang telah ditetapkan (Brown, 2004). Kemudian pengumpulan bukti-bukti untuk menunjukkan dasar saintifik penafsiran skor sebagaimana yang direncanakan (Nurgiyantoro, 2017). 
Tabel 1. Indikator Kelayakan Instrumen Evaluasi

\begin{tabular}{|c|c|c|}
\hline No & Ranah Materi & Ranah Bahasa \\
\hline 1 & Butir instrumen penilaian sesuai dengan indikator. & Rumusan kalimat komunikatif. \\
\hline 2 & $\begin{array}{l}\text { Batasan pertanyaan dan jawaban yang diharapkan } \\
\text { jelas. }\end{array}$ & $\begin{array}{l}\text { Kalimat menggunakan bahasa yang } \\
\text { baik dan benar, sesuai dengan } \\
\text { tingkat perkembangan intelektual, } \\
\text { sosial dan emosional. }\end{array}$ \\
\hline 3 & Isi materi sesuai dengan tujuan pengukuran. & $\begin{array}{l}\text { Rumusan kalimat tidak } \\
\text { menimbulkan penafsiran ganda atau } \\
\text { salah pengertian. }\end{array}$ \\
\hline 4 & $\begin{array}{l}\text { Isi materi yang ditanyakan sesuai dengan } \\
\text { pengembangan metakognisi, daya imajinasi dan } \\
\text { kreativitas berpikir siswa. }\end{array}$ & $\begin{array}{l}\text { Menggunakan bahasa/kata yang } \\
\text { umum (bukan bahasa lokal) }\end{array}$ \\
\hline
\end{tabular}

(Supardi, 2015)

Kriteria kesahihan instrumen evaluasi merujuk pada pengertian "apakah tes itu dapat mengukur apa yang diukur?". Validitas tes yang baik tidak hanya mengukur dan mengungkap tingkatan aspek kognitif yang sederhana, ingatan dan pemahaman saja, melainkan mampu mengungkap tingkatan yang lebih tinggi. Nurgiyantoro (2001) membagi kriteria kesahihan instrumen berdasarkan analisis rasional yaitu kesahihan isi dan kesahihan konstruk. Pelaksanaan penelaah kesahihan isi dapat dilakukan dengan mengidentifikasi dan mencocokkan butir soal untuk mengungkap tingkatan kognitif. Sedangkan, kesahihan konstruk penyusunan butir-butir soal dilandasi dengan kisi-kisi. Supardi (2015) secara kualitatif penilaian kelayakan instrumen evaluasi dapat menekan pada pelbagai aspek materi, konstruk, dan Bahasa. Namun pada penelitian ini difokuskan pada aspek materi dan bahasa. Secara detail kedua ranah dapat dilihat Tabel 1.

Penelitian tentang kelayakan instrumen evaluasi buku teks Bahasa Indonesia siswa kelas XI Kurikulum 2013 revisi 2017 perlu dilakukan karena banyak keluhan dari guru seputar materi dan instrumen evaluasi tidak sesuai dengan kompetensi yang diajarkan. Buku Teks Bahasa Indonesia seharusnya representasi dari penerapan kurikulum 2013 revisi 2018. Buku teks yang diterbitkan pemerintah ditujukan untuk keperluan skala nasional. Secara umum buku teks yang disediakan oleh pemerintah dibuat untuk karakteristik/kondisi siswa Indonesia dan belum dibuat secara khusus sesuai dengan karakteristik siswa. Komponen universal di dalam pembelajaran yang menunjang sarana dan prasarana yang mengacu pada tujuan pendidikan nasional.

Penelitian terdahulu mengenai kelayakan buku isi buku ajar Bahasa Indonesia telah dilakukan oleh Khairunnisa \& Mayrita (2019) Evaluasi Komponen Kelayakan Isi Buku Ajar Bahasa Indonesia: Kesesuaian Materi dengan kurikulum. Penelitian tersebut meneliti buku Cerdas Berbahasa Indonesia penerbit Erlangga. Buku tersebut dapat dijadikan sebagai sumber belajar dalam pembelajaran Bahasa Indonesia kelas X SMA karena materi pada buku ini sesuai dengan silabus kurikulum 2013. Selanjutnya penelitian yang dilakukan oleh Nur Holifatuz Zahro (2019). Penelitian tersebut menekankan 38\% aspek pemahaman. Sehingga buku tersebut dapat diakses oleh guru dan siswa. Penelitian lain dilakukan oleh Safi'i et al. (2020). Penelitian tersebut terfokus pada tingkat kevaliditasan instrumen evaluasi BSE buku teks bahasa Indonesia SMP kelas IX. Kevaliditasan instrumen evaluasi dalam buku tersebut ditinjau dari aspek materi sebesar $25 \%$.

Penelitian yang sedang dilakukan dapat dianggap sebagai kelanjutan dari kajian sebelumnya terhadap kevaliditasan evaluasi buku sekolah elektronik (BSE) 
buku teks bahasa Indonesia SMP kelas IX terbitan Kementerian dan Kebudayaan Republik Indonesia (Safi'i, 2020). Hal ini menunjukkan, bahwa instrumen evaluasi yang dikembangkan dalam BSE terbitan Kementerian dan Kebudayaan Republik Indonesia sebagian besar dapat dikategorikan kurang relevan dengan kompetensi atau materi yang diajarkan. Dimungkinkan pula pada buku sekolah elektronik (BSE) buku teks bahasa Indonesia SMA kelas XI terbitan Kementerian dan Kebudayaan Republik Indonesia memiliki tingkat kevaliditasan yang kurang relevan pula dengan materi dan kompetensi yang diajarkan. Berdasarkan usia perkembangan siswa SMA sudah berada pada tahap operasi formal. Pada tingkatan ini, seorang siswa telah menguasai operasi mental yang kompleks yang menyangkut konsep konkret dan abstrak (Utama et al., 2018). Tahap ini, seorang anak sudah dapat menyusun hipotesis (Listeani, 2020). Sehingga buku teks yang digunakan guru harus memenuhi aspek keruntutan alur pikir terlihat pada kronologi penalaran. Konsep, teori, definisi, rumus, dan kaidah yang terdapat dalam buku teks harus disajikan dengan pola penalaran generasi $\mathrm{Z}$ sehingga dapat diterima.

Diharapkan dengan latar belakang penelitian yang telah dipaparkan, maka tujuan penelitian ini dapat menjadi acuan dalam pembuatan instrumen penilaian siswa sesuai dengan acuan pemerintah dan kondisi lingkungan. Penerapan ilmu evaluasi pelajaran khususnya analisis buku teks bahasa Indonesia kelas XI Kurikulum 2013 revisi 2017. Penelitian ini difokuskan untuk mengetahui kelayakan instrumen evaluasi yang ditinjau dari kelayakan instrumen evaluasi dari aspek materi dan kelayakan instrumen evaluasi dari aspek bahasa dalam buku sekolah elektronik terbitan Kementerian Pendidikan dan Kebudayaan, siswa kelas XI kurikulum 2013 revisi 2017.

\section{B. METODE}

Penelitian ini merupakan penelitian kualitatif dengan pendekatan deskriptif instrumen analisis, dengan menganalisis kesesuaian buku ditinjau dari kelayakan instrumen buku sekolah elektronik. Sumber data penelitian ini adalah buku sekolah elektronik Bahasa Indonesia kelas XI kurikulum 2013 revisi 2017 terbitan Kementerian Pendidikan dan Kebudayaan tahun 2017 dengan penulis Suherli dkk. "Bahasa Indonesia untuk SMA/MA/SMK/MAK Kelas XI Edisi Revisi". Data yang diperoleh melalui deskripsi analisis isi: Kelayakan instrumen evaluasi ditinjau dari Aspek Materi terdiri atas tujuan pengukuran sesuai dengan materi soal; indikator pencapaian sesuai dengan butir soal; materi soal sesuai dengan jenjang Pendidikan siswa SMA; Masalah yang disajikan menarik bagi siswa. Kemudian Kelayakan instrumen evaluasi ditinjau dari Aspek Bahasa terdiri atas Penggunaan bahasa sesuai dengan PEUBI dan komunikatif; Rumusan soal tidak menggunakan bahasa yang berlaku/daerah setempat, tidak menimbulkan penafsiran ganda; dan tidak menggandung kata yang dapat menyakiti perasaan siswa (Supardi, 2015).

Tabel 2. Kategori Kelayakan Buku Teks

\begin{tabular}{cc}
\hline Kriteria & Kategori \\
\hline $85 \%-100 \%$ & Sangat Layak \\
$65 \%-84 \%$ & Layak \\
$55 \%-64 \%$ & Cukup Layak \\
$40 \%-54 \%$ & Tidak Layak \\
$<39 \%$ & Sangat Tidak Layak \\
\hline
\end{tabular}

(BNSP, 2014) 
Instrumen penelitian ini bekerja berdasarkan indikator kelayakan instrumen evaluasi dan panduan kriteria kesahihan instrumen berdasarkan analisis kualitatif butir instrumen penilaian tes menurut Supardi (2015). Instrumen evaluasi bentuk tes uraian dan bentuk tes melengkapi. Penelitian ini memberikan gambaran kelayakan instrumen Buku Sekolah Elektronik (BSE) Bahasa Indonesia siswa Kelas XI Kurikulum 2013 revisi 2017 terbitan Kementerian Pendidikan dan Kebudayaan. Penetapan sampel dilakukan secara purposive didasarkan pada kriteria yang sesuai dengan tujuan penelitian dan dapat menjawab permasalahan penelitian. Data kelayakan instrumen evaluasi ditinjau aspek materi dianalisis dengan melihat keselarasan instrumen evaluasi dan KD yang diajarkan. Semakin banyak instrumen evaluasi yang relevan maka semakin layak instrumen evaluasi pada buku tersebut. Sedangkan kelayakan instrumen evaluasi ditinjau aspek bahasa terdiri atas kejelasan kalimat serta kegunaan bahasa yang sesuai dengan konteksnya. Adapun kategori kelayakan buku teks yang digunakan dalam penelitian ini dipaparkan pada Tabel 2.

Teknik pengumpulan data penelitian ini adalah teknik studi pustaka dan teknik dokumen. Teknik studi pustaka digunakan untuk mendapatkan bahan-bahan dan informasi yang berkenaan dengan data dan masalah yang diteliti. Mencari, menganalisis, dan membuat kerangka berpikir mengenai kelayakan instrumen dalam buku teks elektronik tersebut dan mencari dan mendokumentasikan tulisan dan teori mengenai kelayakan instrumen. Teknik analisis data yang digunakan penelitian ini adalah teknik analisis isi (content analysis).

\section{PEMBAHASAN}

\section{Kelayakan Instrumen Evaluasi Ditinjau dari Aspek Materi}

Data kelayakan instrumen evaluasi ditinjau dari aspek materi diperoleh dari instrumen evaluasi bentuk tes uraian dan bentuk tes melengkapi pada buku sekolah elektronik terbitan Kementerian pendidikan dan kebudayaan bahasa indonesia siswa Kelas XI Kurikulum 2013 revisi 2017 dari ranah materi yang disajikan. Data penelitian instrumen penilaian sebanyak 18 instrumen penilaian yang terdiri atas 16 tes bentuk uraian dan 2 tes bentuk melengkapi. Indikator pada instrumen evaluasi dari aspek materi antara instrumen evaluasi bentuk tes uraian dan bentuk tes melengkapi sama. Sehingga dijadikan satu data analisis.

Instrumen evaluasi ditinjau dari aspek materi memperoleh rerata skor 78,8\%. Sehingga kategori instrumen evaluasi ditinjau dari aspek materi pada buku sekolah elektronik terbitan Kementerian pendidikan dan kebudayaan Bahasa Indonesia siswa Kelas XI Kurikulum 2013 revisi 2017 adalah layak. Analisis kelayakan instrumen evaluasi ditinjau dari aspek materi disajikan dalam Tabel 3.

Tabel 3. Analisis Kategori Kelayakan Instrumen Evaluasi ditinjau dari Aspek Materi

\begin{tabular}{clc}
\hline No & $\begin{array}{l}\text { Komponen Kelayakan Instrumen Evaluasi } \\
\text { ditinjau dari Aspek Materi }\end{array}$ & Skor (\%) \\
\hline 1 & Butir instrumen penilaian sesuai dengan indikator. & 86,11111 \\
2 & Batasan pertanyaan dan jawaban yang diharapkan jelas. & 77,77778 \\
3 & Isi materi sesuai dengan tujuan pengukuran. & 77,77778 \\
4 & Isi materi yang ditanyakan sesuai dengan pengembangan metakognisi, daya & 73,61111 \\
& imajinasi dan kreativitas berpikir siswa. & $\mathbf{7 8 , 8 1 9 4 4}$ \\
\hline
\end{tabular}


Kelayakan instrumen evaluasi ditinjau dari aspek materi mencakup kesesuaian butir instrumen penilaian selaras dengan indikator, batasan pertanyaan dan jawaban diharapkan jelas, isi materi sesuai dengan tujuan pengukuran, dan isi materi yang ditanyakan sesuai dengan pengembangan metakognisi, daya imajinasi dan kreativitas berpikir siswa. berdasarkan indikator tersebut dapat diketahui, bahwa kelayakan instrumen evaluasi dari aspek materi Buku Sekolah Elektronik (BSE) Bahasa Indonesia siswa SMA Kelas XI Kurikulum 2013 revisi 2017 kelayakan rerata sebesar 78,8\%. Instrumen D5-AMU merupakan contoh instrumen yang memenuhi kriteria kelayakan instrumen evaluasi ditinjau dari aspek materi.

1. Apa saja bukti bahwa semua teks di bawah ini berbentuk eksplanasi? Apa pula gagasan umum serta fakta penting di dalam teks tersebut?

a. Pertumbuhan dimulai dari kecambah. Struktur awal yang muncul berupa radikula atau akar primer. Hal ini menunjukkan bahwa yang pertama kali dibutuhkan kecambah adalah air dan kebutuhan untuk melekat pada tanah. Akar primer akan tumbuh secara lateral, membentuk akar sekunder, dan selanjutnya tumbuhlah cabang- cabang menjadi suatu sistem akar.

b. Percabangan suatu bahasa proto menjadi dua bahasa baru atau lebih, serta tiap-tiap bahasa baru itu dapat bercabang pula dan seterusnya, dapat disamakan dengan percabangan sebatang pohon. Pada suatu waktu batang pohon tadi mengeluarkan cabang-cabang baru, lalu tiap cabang bertunas dan bertumbuh menjadi cabang-cabang baru. Cabang-cabang yang baru ini kemudian mengeluarkan rantingranting yang baru. Demikian seterusnya. Begitu pula percabangan pada bahasa.

2. Lakukanlah silang baca dengan salah seorang teman untuk saling memberikan penilaian/tanggapan terhadap hasil kerjamu itu.

(Suherli, dkk, 2017)

Instrumen D5-AMU mencerminkan pencapaian Kompetensi Dasar yaitu "Mengidentifikasi Informasi dalam Teks Eksplanasi". Instrumen tersebut sesuai dengan tujuan yang terdapat pada buku tersebut. Soal yang disajikan dapat menggali kompetensi siswa dalam memahami informasi urutan kejadian dan mengidentifikasi informasi dalam Teks Eksplanasi. Siswa harus memahami terlebih dahulu konsep dasar dari teks eksplanasi. Setelah siswa memahami konsep dasar teks eksplanasi maka siswa diminta untuk mengidentifikasi penggalan beberapa teks kemudian menyertakan alasan mengapa teks tersebut termasuk pada teks eksplanasi. Setelah menemukan alasan masing-masing siswa maka mereka saling memberikan tanggapan dari alasan yang sudah mereka buat.

Instrumen penilaian yang disajikan mencakup materi yang terkandung dalam tujuan pengukuran. Dengan kata lain, instrumen tersebut dapat mengukur aspek yang diajarkan. Nurgiyantoro (2005) menegaskan setiap butir tes, secara jelas harus dapat mengacu tujuan pembelajaran karena terdapat aspek yang diukur. Materi yang ditanyakan sesuai perkembangan metakognisi dan kreativitas berpikir siswa karena materi yang disajikan memiliki kemampuan berkenaan dengan pemahaman dan keterampilan siswa dalam mengidentifikasi informasi dalam teks eksplanasi.

Perkembangan intelektual siswa berproses melalui pengetahuan yang sudah ada dan berkombinasi dengan pengetahuan baru yang ia peroleh. Senada dengan Maman (2019) siswa lebih mudah menyerap ilmu dengan baik jika materi yang 
dipelajarinya berkaitan dengan informasi yang telah diketahuinya. Instrumen ini merupakan Asessment as learning siswa melakukan monitor dan refleksi dalam proses belajar secara mandiri. Oleh karena itu, siswa merupakan pusat pembelajaran yang dianggap dapat memaksimalkan pembelajaran siswa.

Buku Sekolah Elektronik (BSE) Bahasa Indonesia siswa SMA Kelas XI Kurikulum 2013 revisi 2017 merupakan buku teks yang layak dari segi kelayakan instrumen evaluasi ditinjau dari aspek materi. Meskipun instrumen evaluasi sudah dikatakan layak namun terdapat beberapa kekurangan seperti materi ajar yang disajikan dalam buku masih kurang lengkap. Buku Sekolah Elektronik (BSE) Bahasa Indonesia siswa SMA Kelas XI Kurikulum 2013 revisi 2017 terbitan Kementerian Pendidikan dan Kebudayaan dari 20 Kompetensi dasar pengetahuan dan Kompetensi Dasar Keterampilan yang harus disampaikan kurikulum 2013 revisi 2018. Tetapi, hanya ada 16 Kompetensi Dasar yang tersaji dalam buku tersebut tidak semua 16 Kompetensi Dasar tersebut memiliki instrumen penilaian dari segi Pengetahuan. Pada buku tersebut terdapat 2 Kompetensi Dasar Pengetahuan dan 4 Kompetensi Dasar.

Pada dasarnya buku teks pelajaran mempunyai hubungan dengan kurikulum karena penggambaran dan pemaduan kompetensi inti dengan kompetensi dasar yang berkaitan dengan hasil belajar maupun materi pokok yang akan disampaikan. Materi yang disajikan dalam buku pelajaran harus jelas, spesifik, akurat, mutakhir dan sesuai dengan usia perkembangan siswa dalam ilustrasi materi. Sehingga informasi dan materi yang disajikan tidak mengandung makna yang bias. (Efendi, 2009) Dalam pelaksanaan pembelajaran Buku Sekolah Elektronik (BSE) Bahasa Indonesia siswa SMA kelas XI kurikulum 2013 revisi 2017 masih dapat dimanfaatkan dan menjadi sumber belajar utama dengan pendamping sumber belajar yang lain, seperti Internet, Media Cetak, dll.

Temuan tentang kelayakan isi buku ajar Bahasa Indonesia ini berbeda dengan hasil penelitian sebelumnya yang dilakukan oleh Khairunnisa \& Mayrita (2019) yang melakukan kajian kelayakan isi buku ajar "Cerdas Berbahasa Indonesia" kelas X SMA, penerbit Erlangga. Hasil penelitian tersebut dari aspek kelengkapan materi mencapai $80 \%$ berdasarkan kriteria kesesuaian mengacu juga pada 36 kompetensi dasar pada silabus kurikulum 2013.

Berbeda halnya dengan penelitian yang dilakukan peneliti saat ini. Peneliti meneliti kelayakan instrumen evaluasi dari aspek materi. Pada Permendikbud Nomor 37 tahun 2018 tentang Kompetensi Inti dan Kompetensi Dasar pembelajaran pada Kurikulum 2013 pada Pendidikan dasar dan Pendidikan menengah terdapat 20 Kompetensi Dasar yang harus disampaikan. Namun, dari 20 Kompetensi dasar hanya 16 Kompetensi dasar yang terdapat. Kelayakan instrumen evaluasi dari aspek materi memperoleh rerata sebesar 78,8\% dengan kategori Layak. Dalam pelaksanaan pembelajaran Buku Sekolah Elektronik (BSE) Bahasa Indonesia siswa SMA Kelas XI Kurikulum 2013 revisi 2017 terbitan Kementerian Pendidikan dan Kebudayaan masih dapat dimanfaatkan dan menjadi sumber belajar utama dengan pendamping sumber belajar yang lain, seperti Internet, Media Cetak, dll.

\section{Kelayakan Instrumen Evaluasi Ditinjau dari Aspek Bahasa}

Data kelayakan instrumen evaluasi ditinjau dari aspek bahasa diperoleh dari instrumen evaluasi bentuk tes uraian dan bentuk tes melengkapi dari ranah bahasa. 
Data penelitian instrumen penilaian sebanyak 18 instrumen penilaian yang terdiri atas 16 tes bentuk uraian dan 2 tes bentuk melengkapi.

Tabel 4. Analisis Kategori Kelayakan Instrumen Evaluasi ditinjau dari Aspek Bahasa

\begin{tabular}{cll}
\hline No & Komponen Kelayakan Instrumen Evaluasi ditinjau dari Aspek Bahasa & Skor (\%) \\
\hline 1 & Rumusan kalimat komunikatif. & 86,11111 \\
2 & Kalimat menggunakan bahasa yang baik dan benar, sesuai dengan tingkat & 80,55556 \\
& perkembangan intelektual, sosial dan emosional. & \\
3 & Rumusan kalimat tidak menimbulkan penafsiran ganda atau salah & 76,38889 \\
& pengertian. & 86,11111 \\
4 & Menggunakan bahasa/kata yang umum (bukan bahasa lokal) & $\mathbf{8 4 , 7 2 2 2 2 2}$ \\
\hline
\end{tabular}

Indikator pada instrumen evaluasi dan panduan kriteria kesahihan instrumen dari aspek bahasa dengan instrumen evaluasi bentuk tes uraian dan bentuk tes melengkapi sama (Supardi, 2015). Sehingga dijadikan satu data analisis. Instrumen evaluasi ditinjau dari aspek bahasa memperoleh rerata skor $84,7 \%$ sehingga kategori instrumen evaluasi ditinjau dari aspek bahasa adalah layak. Analisis kelayakan instrumen evaluasi ditinjau dari aspek bahasa disajikan dalam Tabel 4.

Kelayakan instrumen evaluasi ditinjau dari aspek bahasa mencakup kesesuaian butir instrumen penilaian dengan indikator, yaitu menggunakan bahasa yang sesuai dengan konteksnya, menggunakan kalimat komunikatif, tidak menggunakan bahasa setempat, tidak menggandung kosakata yang dapat menyinggung perasan, dan bahasa tidak menimbulkan ambiguitas. Hasil penelitian yang dilakukan, tingkat kelayakan instrumen evaluasi pada aspek bahasa memiliki kelayakan tertinggi jika dibandingkan aspek materi yaitu rerata sebesar 84,7\%. Hal ini menunjukkan sebagian besar instrumen evaluasi sudah menggunakan kalimat efektif. Namun masih ditemukan instrumen evaluasi yang ambigu. Contoh instrumen yang ambigu yaitu Instrumen D3-AMU.

1. Menjelaskan apakah teks di atas?

2. Teks tersebut berkategori apa: tentang kebiasaan, aktivitas tertentu, atau penggunaan alat? Jelaskan alasan-alasannya!

3. Buktikan bahwa teks tersebut disusun secara kronologis!

(Suherli, dkk, 2017)

Instrumen D3-AMU terdapat tiga soal bermakna ambigu. Kalimat nomor satu, dapat bermakna menjelaskan struktur teks atau menjelaskan ide pokok teks yang disajikan. Kompetensi Dasar yang diajarkan adalah memahami isi teks prosedur. Oleh karena itu, perbaikan kalimat nomor satu agar tidak mengandung makna ambigu yang tepat adalah Apakah ide pokok dalam teks Empat Tips agar Tidak Iri kepada Orang lain?

Selanjutnya, keambiguan dari kalimat struktur soal nomor dua adalah terletak pada frasa "Teks tersebut berkategori apa". Frasa selanjutnya menyebutkan jenisjenis tema. Pada dasarnya jenis tema tersebut sudah dijelaskan di materi ini, dapat dimungkinkan bahwa siswa akan mengetahui jenis tema yang dimaksudkan. Jika kalimat tersebut disebutkan secara lisan mungkin pasangan tutur akan mengetahui 
maksud yang disampaikan karena penutur dapat memanfaatkan peragaan, gestur, intonasi dan mimik wajah. Sedangkan bahasa tulis harus jelas keterkaitan unsur gramatikalnya; tegas (tidak rancu), tepat pemilihan kata/istilahnya dan lugas (tidak bertele-tele) (Sugono, 2009). Oleh karena itu, agar tidak mengandung kata ambigu, kalimat yang tepat adalah Jelaskan tema dalam teks prosedur tersebut?

Kalimat soal nomor tiga dapat bermakna ambigu karena bisa dimungkinkan kalimat tersebut meminta siswa untuk membuktikan teks melalui peristiwa-peristiwa yang nyata dialami mereka atau membuktikan teks dengan kalimat yang terdapat pada teks tersebut. Oleh karena itu, agar tidak mengandung kata yang ambigu, bisa dimungkinkan kalimat yang tepat pada soal nomor tiga adalah Buatlah beberapa bukti teks tersebut melalui peristiwa yang pernah kamu alami! atau Buatlah beberapa kalimat yang membuktikan bahwa teks tersebut disusun secara kronologis! Pada dasarnya kalimat tanya merupakan kalimat yang membutuhkan suatu jawaban (Pandean, 2018). Sehingga kalimat yang disampaikan dapat menyampaikan pesan/informasi secara tepat.

Penggunaan kalimat efektif pada instrumen evaluasi perlu diperhatikan karena membangun pemahaman siswa yang tepat. Jika penggunaan kalimat tidak efektif dalam instrumen evaluasi maka akan menimbulkan persepsi yang salah. Akhirnya siswa akan mengalami kesulitan dalam menjawab soal tersebut. Faktor-faktor yang mempengaruhi pemahaman siswa dalam membaca yaitu struktur sintaksis, semantik leksikal, pengalaman bahasa dan daya pemahaman siswa (de Ruiter et al., 2020).

Tingkat kelayakan instrumen evaluasi dari segi bahasa serupa dengan hasil penelitian Safi'i et al. (2020). Pada Buku Sekolah Elektronik (BSE) Bahasa Indonesia siswa SMA Kelas IX Kurikulum 2013 terbitan Kementerian dan Kebudayaan Republik Indonesia yang mempunyai kevaliditasan instrumen dari ranah bahasa sebesar $92 \%$. Hal tersebut serupa dengan penelitian ini yang menunjukkan, bahwa dari segi indikator kebahasaan telah terpenuhi dengan baik. Bahasa yang digunakan sesuai dengan tingkat perkembangan siswa sehingga mudah untuk dipahami.

Berbeda penelitian yang dilakukan oleh Yusuf Hendrawanto dan Mimi Mulyani (Hendrawanto \& Mulyani, 2017) yang meneliti buku teks Bahasa Indonesia kelas XII semester 1 SMA (2015) terbitan Kemendikbud. Penelitian tersebut mengungkapkan bahwa aspek kebahasaan dalam buku tersebut kurang layak. Wacana yang disajikan terlalu mudah dipahami siswa dan memiliki keterbacaan yang rendah sehingga mendapatkan skor 50,97. Hal yang perlu diperhatikan dalam kebahasaan yaitu: kesesuaian pemakaian bahasa dengan tingkat perkembangan siswa; pemakaian bahasa yang komunikatif; pemakaian bahasa memenuhi syarat keruntutan dan keterpaduan alur berpikir (Muslich, 2010).

Berbeda halnya dengan penelitian yang dilakukan yaitu kelayakan instrumen evaluasi dari aspek bahasa dalam Buku Sekolah Elektronik (BSE) Bahasa Indonesia siswa SMA Kelas XI Kurikulum 2013 revisi 2017 terbitan Kementerian Pendidikan dan Kebudayaan mempunyai kelayakan sebesar 84,7\%. Hal ini menunjukkan instrumen evaluasi dari indikator kebahasaan terpenuhi dengan baik. Pada instrumen evaluasi bahasa yang digunakan sesuai dengan tingkat pemahaman dan perkembangan siswa. Sehingga, siswa lebih mudah memahami tujuan yang akan disampaikan. 


\section{PENUTUP}

Kelayakan Instrumen Evaluasi dalam Buku Sekolah Elektronik (BSE) Bahasa Indonesia siswa SMA Kelas XI Kurikulum 2013 revisi 2017 ditinjau dari aspek Bahasa sebesar 84,7\% dengan katagori layak. Hal ini menunjukkan bahwa indikator kebahasaan pada instrumen evaluasi terpenuhi dengan baik. Bahasa yang digunakan pada instrumen evaluasi sesuai dengan tingkat pemahaman dan perkembangan siswa SMA. Sehingga, siswa lebih mudah memahami tujuan yang akan disampaikan. Selain itu hasil penelitian ini dapat memberikan saran bagi guru dalam menelaah dan memilih kualitas buku, terutama kelayakan instrumen evaluasi ditinjau dari aspek materi dan aspek Bahasa dan hasil penelitian ini dapat memberikan sumbangsih bagi Pusat Perbukuan dan Kurikulum dalam penyusunan buku teks pelajaran selanjutnya agar mempertimbangkan Kompetensi Dasar yang diajarkan dan kelayakan instrumen evaluasi ditinjau dari aspek materi dan aspek Bahasa.

\section{DAFTAR PUSTAKA}

Arikunto, S., \& Abdul, J. C. (2010). Evaluasi Program Pendidikan: Pedoman Teoretis Praktis Bagi Mahasiswa dan Praktisi Pendidikan. Edisi Kedua. Jakarta: Bumi Aksara

Brown, H. D. (2004). Language Assessment: Principles and Classroom Practices. United States of America: Longman.

Badan Standar Nasional Pendidikan dan Pusat Perbukuan. (2014). Instrumen Penilaian Buku Teks Pelajaran Tahun 2014. https://bsnpindonesia.org/2014/05/instrumen-penilaian-buku-teks-pelajaran-tahun-2014/

de Ruiter, L. E., Lieven, E. V. M., Brandt, S., \& Theakston, A. L. (2019). Interactions Between Givenness and Clause Order in Children's Processing of Complex $\begin{array}{llll}\text { Sentences. } & \text { Cognition, } & \text { 198(2), }\end{array}$ https://doi.org/10.1016/j.cognition.2019.104130

Earl. Lorna M. (2013). Assessment as Learning: Using Classroom Assessment to Maximize Student Learning Second Edition. California: SAGE Publications Asia-Pacific.

Efendi, A. (2009). Beberapa Catatan tentang Buku Teks Pelajaran di Sekolah. INSANIA: Jurnal Pemikiran Alternatif Kependidikan, 14(2), 1-10. https://doi.org/10.24090/insania.v14i2.334

Hapsari, T. P. R. N., \& Wulandari, A. (2020). Analisis Kelayakan Buku Ajar Milenial Berbasis Augmented Reality (AR) sebagai Media Pembelajaran Teks Prosedur di Magelang. Diglosia: Jurnal Kajian Bahasa, Sastra, dan Pengajarannya, 3(4), 351-364. https://doi.org/10.30872/diglosia.v3i4.125

Hendrawanto, Y., \& Mulyani, M. (2017). Kelayakan Kebahasaan dan Isi Buku Teks Bahasa Indonesia Kelas XII Semester 1 SMA. JPBSI: Jurnal Pendidikan Bahasa dan Sastra, 2(2), 58-62. http://dx.doi.org/10.26737/jp-bsi.v2i2.246

Huang, P. (2019). Learning, Culture and social interaction textbook interaction: A study of the language and cultural contextualisation of English learning textbooks. Learning, Culture and Social Interaction, 21(2018), 87-99. https://doi.org/10.1016/j.lcsi.2019.02.006

Khairunnisa, F., \& Mayrita, H. (2019). Evaluasi Komponen Kelayakan Isi Buku Ajar Bahasa Indonesia: Kesesuaian Materi dengan Kurikulum. Jurnal Penelitian Pendidikan Bahasa dan Sastra, 4(1), 408-416. https://doi.org/10.32696/ojs.v4i1.220 
Listeani, F. Y. (2020). Penggunaan Kosakata Bahasa Indonesia Pada Generasi Millenial. Basastra, 9(1), 1-15. https://doi.org/10.24114/bss.v9i1.17771

Muslich, M. (2010). Text Book Writing: Dasar-dasar Pemahaman, Penulisan, dan Pemakaian Buku Teks. Yogyakarta: Ar-Ruzz Media.

Nurgiyantoro, B. (2001). Penilaian dalam Pengajaran Bahasa dan Sastra. Edisi Ketiga. Yogyakarta: BPFE Yogyakarta.

Nurgiyantoro, B.. (2015). Penilaian Otentik: Dalam Pembelajaran Bahasa. Yogyakarta: Gadjah Mada University Press.

Nurgiyantoro, B.. (2017). Penilaian Pembelajaran Bahasa Berbasis Kompetensi. Yogyakarta: BPFE Yogyakarta.

Pandean, M. (2018). Kalimat Tanya dalam Bahasa Indonesia. Kajian Linguistik, 5(3), 75-88. https://doi.org/10.35796/kaling.5.3.2018.25030

Safari. (2019). Evaluasi Pendidikan: Penyusunan Kisi-Kisi, Penulisan, dan Analisis Butir Soal Berdasarkan Kurikulum 2013 Menuju Penilaian Abad 21. Jakarta: Erlangga

Safi'i, I., \& Yanti, P. G. (2019). Mengidentifikasi Model Pengembangan Instrumen Evaluasi dalam E-Book Buku Teks Bahasa Indonesia. Pembelajar: Jurnal Ilmu Pendidikan, Keguruan, dan Pembelajaran, 3(1), 9-18. https://doi.org/10.26858/pembelajar.v3i1.12603

Safi'i, I., Listeani, F. Y., \& Tarmini, W. (2020). Kevaliditasan Instrumen Evaluasi dalam BSE Buku Teks Bahasa Indonesia Tahun Pelajaran 2019/2020. Komposisi: Jurnal Pendidikan Bahasa dan Seni, 21(1), 31-43. https://doi.org/10.24036/komposisi.v21i1.108716

Sugono, D. (2009). Mahir Berbasa Indonesia dengan Benar. Jakarta: PT Gramedia Pustaka Utama.

Supardi. (2015). Penilaian Autentik Pembelajaran Afektif, Kognitif, dan Psikomotor. Jakarta: Rajawali Pers.

Suryaman, Maman. (2019). Dimensi-Dimensi Kontekstual di Dalam Penulisan Buku Teks Pelajaran Bahasa Indonesia. DIKSI: Jumal Ilmiah Bahasa, Sastra dan Pengajarannya, 13(2), 165-178. https://doi.org/10.21831/diksi.v13i2.6456

Utama, Z. P., Maison, Syarkowi, A. (2018). Analisis Kemampuan Bernalar Siswa SMA Kota Jambi. Jurnal Penelitian Pembelajaran Fisika, 9(1), 1-5. https://doi.org/10.26877/jp2f.v9i1.2223

Wisiasworo, E. (2019). Guru Ideal di Era Digital. Depok: Huta Parhapuran.

Yusuf, A. M. (2017). Asesmen dan Evaluasi Pendidikan. Jakarta: Prenadamedia Group. Zahro, N. H. (2019). Uji Kompetensi Pada Buku Sekolah Elektronik (BSE). Jurnal IKA PGSD (Ikatan Alumni PGSD) UNARS, $7(2), \quad 134-149$ https://doi.org/10.36841/pgsdunars.v7i2.480 
